\title{
Outbreak of Sciaenacotyle panceri (Monogenea) on cage-reared meagre Argyrosomus regius (Osteichthyes) from the western Mediterranean Sea
}

\author{
Paolo Merella ${ }^{1, *}$, Santino Cherchi ${ }^{2}$, Giovanni Garippa1 ${ }^{1}$, Maria Letizia Fioravanti ${ }^{3}$, \\ Andrea Gustinelli ${ }^{3}$, Fulvio Salati ${ }^{2}$
}

${ }^{1}$ Division of Parasitology and Parasitological Diseases, Department of Animal Biology, Sassari University, Via Vienna 2, 07100 Sassari, Italy

${ }^{2}$ Fish Disease and Aquaculture Center, Istituto Zooprofilattico Sperimentale della Sardegna, State Veterinary Institute, Via Parigi s.n., 09170 Oristano, Italy

${ }^{3}$ Department of Veterinary Public Health and Animal Pathology, Bologna University, Via Tolara di Sopra 50, 40064 Ozzano Emilia, Bologna, Italy

\begin{abstract}
Two different batches of meagre Argyrosomus regius were stocked in the same floating cage located in north-eastern Sardinia (western Mediterranean Sea). After 4 mo, the fish started showing non-specific disease signs, such as lethargy, emaciation, gill anaemia and mortality. In total 65 specimens of meagre of both stocks were sampled for parasitological and microbiological analysis, and only 1 species of parasite, the microcotylid monogenean Sciaenacotyle panceri, was found on the gills of caged meagre. No protozoan or other metazoan parasites were found and no bacteria or viruses were isolated. After the outbreak, a total mortality rate of 5 to $10 \%$ was estimated for the older fish stock, while no noteworthy mortality was recorded in younger fish $(<2 \%)$. This is the first account of $S$. panceri on the gills of cultured meagre as causative agent of disease and mortality. The effects of the presence of this parasite emphasise the need for disease control strategies of cultured meagre, and investigating the transfer of microcotylids from wild to caged fish.
\end{abstract}

KEY WORDS: Sciaenacotyle panceri $\cdot$ Argyrosomus regius $\cdot$ Disease $\cdot$ Monogenea $\cdot$ Sea-cage aquaculture

Resale or republication not permitted without written consent of the publisher

\section{INTRODUCTION}

Among the emerging parasites of cultured marine fish, blood-feeding polyopisthocotyleans are one of the most important groups (Leong \& Colorni 2002). Although there is a general opinion that these parasites are not harmful in natural conditions (Kearn 2004), in intensively cultured fish they may reach high intensities and produce injuries such as emaciation, lethargy, anaemia, and severe gill lesions (Montero et al. 2004, Merella et al. 2005, Hayward et al. 2007).

Sciaenacotyle panceri (Sonsino) is a microcotylid monogenean parasitic on the gills of the sciaenid fish shi drum Umbrina cirrosa (L.) from the Mediterranean Sea (Tyrrhenian Sea off Pisa, Sonsino 1891; Gulf of Tunis, Ktari 1970) and the eastern Atlantic (off Casablanca, Ktari 1970); it was also recorded on 1 single specimen of another sciaenid, the meagre Argyrosomus regius (Asso) from the Mediterranean Sea (Ktari 1970). A. regius is a benthopelagic species widespread in the east-central Atlantic from Norway to Congo, the Mediterranean and the Black Sea (Froese \& Pauly 2009). This fish can grow up to $230 \mathrm{~cm}$ and reach $103 \mathrm{~kg}$, and it is considered as a potential species for the diversification of aquaculture production in the Mediterranean Sea. 
In August 2005 and July 2006, 2 different batches of meagre (Stock 1, $\mathrm{n}=93442$; Stock 2, $\mathrm{n}=45000$ ) produced in a south France hatchery, were stocked in 2 adjacent offshore floating $4000 \mathrm{~m}^{3}$ cages for commercial purposes. The cages were located in north-eastern Sardinia (western Mediterranean Sea) at a depth of about $30 \mathrm{~m}$. The individual weight at stocking was around $8.3 \mathrm{~g}$ for both groups. In May 2007 both batches were joined in a single $4000 \mathrm{~m}^{3}$ cage (mean weights: Stock $1=750 \mathrm{~g}$, Stock $2=200 \mathrm{~g}$ ). Stocks 1 and 2 were easily distinguished because of the significant difference in size, with non-overlapping size ranges. In September 2007, the fish showed non-specific disease signs, such as lethargic swimming, followed by emaciation, gill anaemia and mortality; these signs were particularly evident in Stock 1. Due to the lack of registered anthelmintics for aquaculture in Italy, the disease was only controlled by husbandry practices, i.e. removing moribund and dead fish from the surface by hand-nets and from the bottom by SCUBA divers, reducing the feeding amount, and harvesting healthy commercial fish as soon as possible.

This paper reports for the first time the infection with Sciaenacotyle panceri on the gills of cage-reared meagre in the western Mediterranean Sea (Sardinia), and describes the pathological signs and mortalities caused by the outbreak of this parasitic disease.

\section{MATERIALS AND METHODS}

From September 2007 to January 2008, a combined total of 65 specimens of meagre from both stocks were examined for parasitological and microbiological analysis (Table 1). Body surface, mouth, gills, body cavity and all organs were examined under a stereo microscope for metazoan parasites, fresh scrapings of the internal organs were observed using a light microscope, from $100 \times$ to $1000 \times$ magnification, for myxozoans and protozoan parasites. Prevalence, range of intensity and mean intensity were calculated according to Bush et al. (1997). Confidence intervals of prevalence and mean intensity, Fisher's exact test and

Table 1. Argyrosomus regius. Summary of sampling data

\begin{tabular}{|lcc|}
\hline Date & $\begin{array}{c}\text { Stock 1 } \\
\text { n (weight g) }\end{array}$ & $\begin{array}{c}\text { Stock 2 } \\
\text { n (weight g) }\end{array}$ \\
\hline Sep 07 & $23(780-1150)$ & $4(190-230)$ \\
Oct 07 & $13(950-1500)$ & $9(170-308)$ \\
Nov 07 & - & $5(372-457)$ \\
Jan 08 & - & $11(211-359)$ \\
Total & $36(780-1500)$ & $29(170-457)$ \\
\hline
\end{tabular}

bootstrap $t$-test, for the comparison of prevalences and mean intensities, respectively, were performed using the free software Quantitative Parasitology 3.0 (Reiczigel \& Rózsa 2005). Microbiological examination was carried out by classical methods as described by Viale et al. (2006).

\section{RESULTS}

In September 2007 the presence of yellowish-brown clumps and dark-grey helminths was detectable by naked eye on the gills of all caged meagre (Fig. 1A, authors' pers. obs.). At necropsy, the gills were pallid with hypersecretion of mucus, and the visceral organs, in particular liver and often heart and spleen, were pale, showing a status of anaemia. After microscopic examination the clumps were recognized as clusters of fusiform eggs entangled by a single filament (Fig. 1B), and the parasites were identified as Sciaenacotyle panceri (Fig. 1C) according to the criteria given by Sonsino (1891) and Ktari (1970), although the range of counts of spines of the genital atrium (Fig. 1D) was wider (20 specimens): external row, 38-66 vs. 40-50; 2nd row, 31-52 vs. 30-45; 3rd rows, 24-39 vs. 25-35. During the survey no bacteria or viruses were isolated, and no protozoan or other metazoan parasites were found. Prevalence $(P)$ and mean intensity $(I)$ of $S$. panceri (Fig. 2) were exceptionally high in September $(P=100 \%$ in both groups, Mean $I=367$ and 200 in Stock 1 and 2, respectively), and in October, prevalence remained high and mean intensity decreased significantly. Finally, all the Stock 1 fish were sold, therefore reducing the stocking density and removing from the cage the most infected and susceptible fish group; infection in Stock 2 decreased and no other pathology was observed after October 2007. Monthly mean intensity of Stock 1 was significantly higher than in Stock 2, while no significant difference was found in prevalences. After the outbreak a total mortality rate of 5 to $10 \%$ was estimated for Stock 1, while no noteworthy mortality was recorded in Stock $2(<2 \%)$.

\section{DISCUSSION}

The massive infection of Sciaenacotyle panceri on the gills of cage-reared Argyrosomus regius was associated with emaciation, anaemia and mortality. It is noteworthy that in the Mediterranean this host may harbour 8 other specific monogenean species (Euzet et al. 1993), but despite the long time that the fish were kept in cages, none of these other parasites were found in examined hosts, and no other parasites were detected. This is the first report of $S$. panceri on cul- 
tured meagre as a causative agent of disease and mortality. Although fry were not examined at stocking, their health status was certified by the veterinarians of the hatchery, and it is unlikely that the fish were already infected on arrival from the hatchery, where they were kept in tanks supplied with filtered water. A feasible hypothesis is that the parasites were acquired from wild fish living around the cages, e.g. A. regius, or more likely the more common Umbrina cirrosa. In fact, the free circulation of water in cages allows the

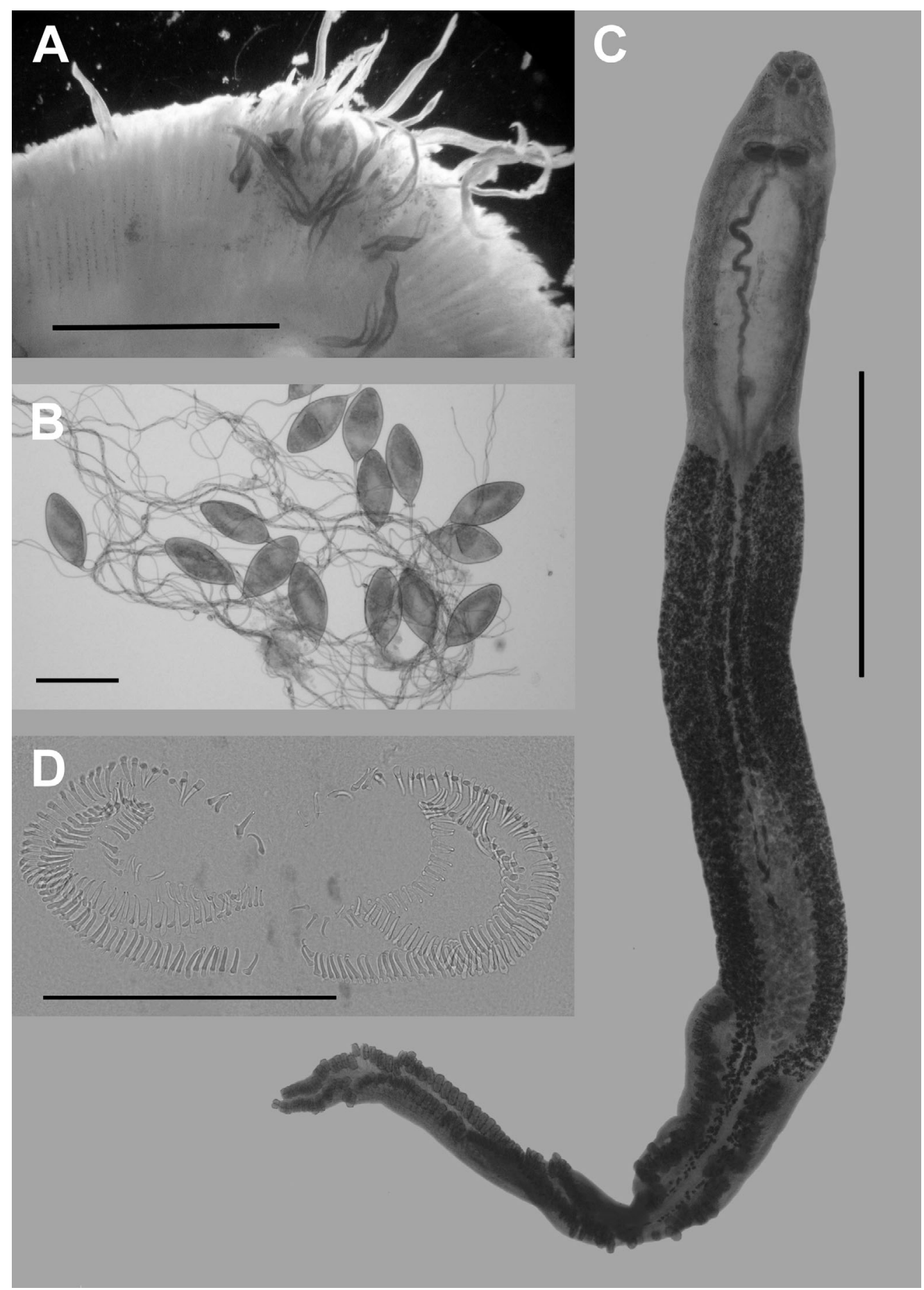

Fig. 1. Sciaenacotyle panceri infecting Argyrosomus regius. (A) Gills of A. regius infected with $S$. panceri. (B) Eggs entangled by the single filament. (C) S. panceri, whole view. (D) Details of the genital atrium. Scale bars = (A) $20 \mathrm{~mm},(\mathrm{~B}, \mathrm{D}) 200 \mu \mathrm{m},(\mathrm{C}) 2 \mathrm{~mm}$ 

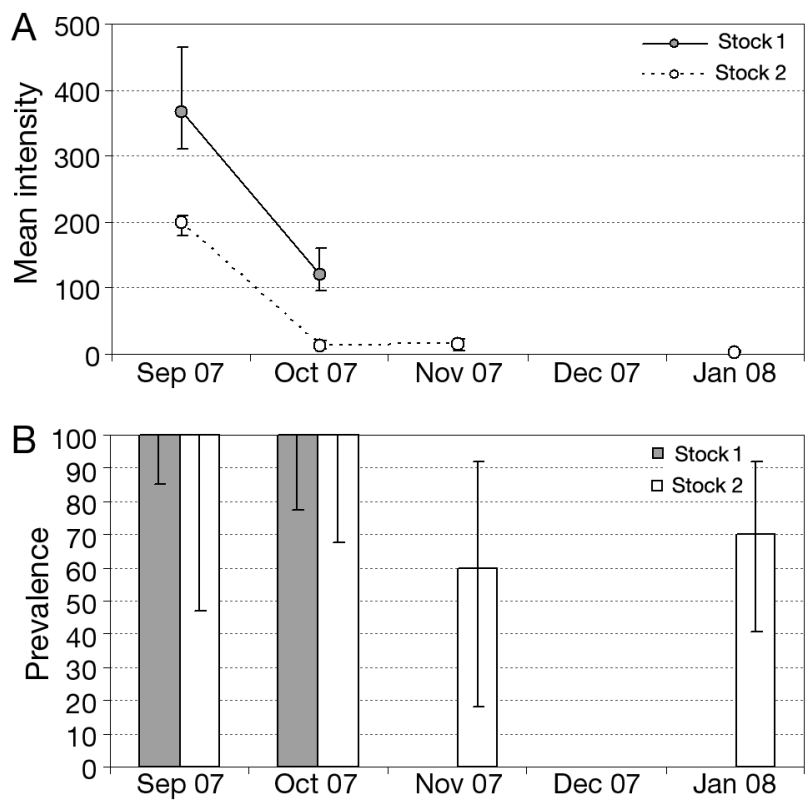

Fig. 2. Sciaenacotyle panceri infecting Argyrosomus regius. Monthly (A) mean intensity and (B) prevalence. Error bars: $95 \%$ confidence intervals

uncontrolled entrance of parasites, particularly ectoparasites with direct life cycles and free swimming larvae like monogeneans (Leong \& Colorni 2002). Moreover, in caged fish, factors such as high stocking density, low genetic diversity, adverse environmental conditions, and/or poor animal husbandry practices, may increase the susceptibility of hosts, promoting parasite transmission and favouring infections and epizootics by unusual parasites (Paperna 1987, Kent 2000, Leong \& Colorni 2002).

Both fish batches were kept in the same cage for 5 mo before the outbreak, and the differences in intensity of infection and mortality between the 2 groups could be due to a pre-existing infection in older fish with transmission to younger ones only after the cohabitation. The higher density for Stock 1 before transfer to the single cage could have led to a higher susceptibility of these fish to the parasite; furthermore, differences in host susceptibility could also be attributed to genetic factors (Buchmann \& Lindenstrøm 2002), e.g. the differences in the host resistance of Atlantic salmon Salmo salar L. to the monogenean Gyrodactylus salaris Malmberg (Bakke et al. 1990).

Probably the outbreak arose in September related to the time of reproduction of the parasite, which generally is strictly restricted for oviparous monogeneans. The great quantity of eggs packed in adult worms and released in long strings, showed an overstated rate of reproduction and easy transmission of Sciaenacotyle panceri to Argyrosomus regius in aquaculture condi- tions. These clumps of eggs form light masses with large surface area that are easily dispersed by currents, and may become entangled in the gills, reinfecting the same host, or drift into cages, favouring fishto-fish transmission. Analogous phenomena were reported by Kearn et al. (1992) and Montero et al. (2004), both of whom observed similar clusters of eggs of the heteraxinids Heteraxine heterocerca (Goto) and Zeuxapta seriolae (Meserve) on Seriola quinqueradiata Temminck \& Schlegel and Seriola dumerili (Risso), respectively.

This is the second report of a microcotylid from farmed Argyrosomus spp. Hayward et al. (2007) reported Sciaenacotyle sciaenicola (Murray) on the gills of cage-reared mulloway Argyrosomus japonicus (Temminck \& Schlegel) in Australia and predicted that this host will be highly likely to develop anaemia during epizootics of this parasitic species. Considering that meagre, and sciaenids in general, are relatively new to aquaculture, the presence of these parasites points out the need for improving disease control strategies of cultured meagre and investigating the possible transfer of microcotylids from wild to caged fish to better prevent future disease outbreaks.

Acknowledgements. We thank the owners and the staff of the aquaculture facility for the collaboration during the sampling and Dr. L. Alborali, IZS of Lombardia and Emilia Romagna, for suggestions and help on Nodavirus investigations. This research was supported by Fondazione Banco di Sardegna 2008.

\section{LITERATURE CITED}

Bakke TA, Jansen PA, Hansen LP (1990) Differences in the host resistance of Atlantic salmon, Salmo salar L., stocks to the monogenean Gyrodactylus salaris Malmberg, 1957. J Fish Biol 37:577-587

Buchmann K, Lindenstrøm T (2002) Interactions between monogenean parasites and their fish hosts. Int J Parasitol 32:309-319

Bush AO, Lafferty KD, Lotz JM, Shostak AW (1997) Parasitology meets ecology on its own terms: Margolis et al. revisited. J Parasitol 83:575-583

Euzet L, Combes C, Caro A (1993) A checklist of Monogenea of Mediterranean fish. In: Lambert A (ed) Proc 2nd Int Symp Monogenea. Montpellier/Sète, 5-8 July 1993, p 1-11

Froese R, Pauly D (2009) FishBase. Accessed 17 Mar. www. fishbase.org

Hayward CJ, Bott NJ, Itoh N, Iwashita M, Okihiro M, Nowak BF (2007) Three species of parasites emerging on the gills of mulloway, Argyrosomus japonicus (Temminck and Schlegel, 1843), cultured in Australia. Aquaculture 265: $27-40$

Kearn GC (2004) Leeches, lice and lampreys. A natural history of skin and gill parasites of fishes. Springer, Dordrecht

Kearn GC, Ogawa K, Maeno Y (1992) Hatching patterns of the monogenean parasites Benedenia seriolae and Heteraxine heterocerca, from the skin and gills, respectively, of 
the same host fish Seriola quinqueradiata. Zool Sci 9: 451-455

Kent ML (2000) Marine netpen farming leads to infections with some unusual parasites. Int J Parasitol 30:321-326

Ktari MH (1970) Microcotyle panceri Sonsino, 1891 (Monogenea - Microcotylidae) parasite d'Umbrina cirrhosa L. dans le golfe de Tunis. Bull Inst Natl Sci Tech Océanogr Pêche Salammbô 1:169-180

Leong TS, Colorni A (2002) Infectious diseases of warmwater fish in marine and brackish waters. In: Woo PTK, Bruno W, Lim SLH (eds) Diseases and disorders of finfish in cage culture. CAB International, Wallingford, p 193-230

Merella P, Cherchi S, Salati F, Garippa G (2005) Parasitological survey of sharpsnout seabream Diplodus puntazzo (Cetti) reared in sea cages in Sardinia (western Mediterranean). Bull Eur Assoc Fish Pathol 25:140-147

Montero FE, Crespo S, Padrós F, De la Gándara F, García A,

Editorial responsibility: Sven Klimpel,

Düsseldorf, Germany
Raga JA (2004) Effects of the gill parasite Zeuxapta seriolae (Monogenea: Heteraxinidae) on the amberjack Seriola dumerili Risso (Teleostei: Carangidae). Aquaculture 232: 153-163

Paperna I (1987) Solving parasite-related problems in cultured marine fish. Int J Parasitol 17:327-336

Reiczigel J, Rózsa L (2005) Quantitative parasitology 3.0. Budapest. Distributed by the authors (www.zoologia.hu/ qp/qp.html)

Sonsino P (1891) Di un nuovo Microcotyle raccolto dal Umbrina cirrhosa. Atti Soc Toscana Sci Nat Resid Pisa 7: 303-304

Viale I, Angelucci G, Kusuda R, Salati F (2006) Immunization of European sea bass, Dicentrarchus labrax L., fingerlings with a commercial vaccine against vibriosis: a one year survey on antibody level, diseases and growth. J Appl Aquacult 18:53-67

Submitted: April 22, 2009; Accepted: July 5, 2009

Proofs received from author(s):September 3, 2009 